\title{
ANÁLISE DA PRODUÇÃO ACADÊMICA BRASILEIRA EM MEDIÇÃO DE DESEMPENHO E MODELOS DE GESTÃO
}

\section{PERFORMANCE MEASUREMENT AND MANAGEMENT MODELS BRAZILIAN ACADEMIC PRODUCTION ANALYSIS}

\author{
Elias Hans Dener Ribeiro da Silva ${ }^{1}$; Edson Pinheiro de Lima ${ }^{2}$; Sérgio Eduardo Gouvêa da Costa ${ }^{3}$ \\ ${ }^{1}$ Pontifícia Universidade Católica do Paraná - PUCPR - Curitiba - Brasil \\ eliashans@,hotmail.com \\ ${ }^{2}$ Pontifícia Universidade Católica do Paraná - PUCPR - Curitiba - Brasil \\ e.pinheiro@pucpr.br \\ ${ }^{3}$ Pontifícia Universidade Católica do Paraná - PUCPR - Curitiba - Brasil \\ s.gouvea@pucpr.br
}

\begin{abstract}
Resumo
É cada vez mais notória a necessidade das empresas desenvolverem modelos de gestão alinhados à estratégia organizacional para que haja integração e flexibilidade em suas operações, visando o dinâmico e atual ambiente de negócios global. O presente artigo tem como objetivo a análise da produção acadêmica brasileira em Engenharia de Produção sobre o tema medição de desempenho e modelos de gestão no periodo de 1998 a 2008. Utilizando dados dos anais do ENEGEP e na base de dados Scielo foi feita uma pesquisa de caráter bibliográfico e alguns dados foram analisados, tais como os anos de maior publicação, entidades de ensino e pesquisa, referências citadas, autores e palavras-chave. Os resultados foram comparados aos trabalhos de Marr e Schiuma (2003), Nelly (2005) e Ruy e Martins (2006), onde foi constatada grande convergência de resultados, além da constatação de uma grande concentração de publicações a respeito do balanced scorecard, $o$ modelo proposto por Kaplan e Norton (1996) que alavancou o estudo sobre os SMD's.
\end{abstract}

Palavras-chave: revisão bibliográfica; ENEGEP; Scielo; medição de desempenho; modelos de gestão.

\section{Introdução}

A medição de desempenho vem despertando um crescente interesse tanto por parte da indústria como da comunidade acadêmica, sendo considerado um elemento essencial para o gerenciamento das empresas (COSTA, 2002) e nos últimos anos vem ganhando reconhecimento crescente do seu importante papel como elemento para gestão eficaz e eficiente das organizações (KENNERLEY; NEELY, 2002). Vários motivos têm feito com que a medição do desempenho tenha ganhado interesse da comunidade de negócios (NEELY, 1999), e são eles: a mudança na 
natureza dos negócios, a competitividade cada vez mais acirrada, as novas iniciativas de melhoramento em operações e a mudança nas demandas externas.

Ao longo da história, medidas de desempenho têm sido usadas para avaliar o sucesso de organizações, onde as técnicas contábeis contemporâneas originaram-se na idade média com concentração em critérios financeiros (CORRÊA, 2004), porém, com clientes mais exigentes e mercados cada vez mais competitivos veio a necessidade de habilidades melhoradas e de respostas rápidas, além da inserção de aspectos externos às considerações atuais.

Vários acadêmicos renomados abordam este tema em questão, entre os mais importantes podem ser citados Robert Kaplan e David Norton, desenvolvedores do modelo de gestão estratégica mais reconhecido e utilizado atualmente, o BSC (Balanced Scorecard), e Andy Neely, desenvolvedor de um dos sistemas de medição de desempenho mais promissores da atualidade, denominado "Pirâmide de Desempenho" (Performance Prism). Outros autores e suas contribuições sobre o tema serão relatados mais adiante.

As pesquisas bibliográficas têm por objetivo conhecer as diferentes contribuições científicas disponíveis sobre determinado tema e dar suporte a todas as fases de qualquer tipo de pesquisa e, segundo Luna (1997), contribuem para a obtenção de informações sobre a situação atual do tema pesquisado e conhecer publicações existentes e aspectos que já foram abordados.

Esta pesquisa tem como objetivo a análise da produção acadêmica na área de medição de desempenho e para este fim foi usada uma metodologia de revisão bibliográfica nos anais do ENEGEP dos anos de 1998 a 2008 e na base do Scielo, onde o critério de pesquisa adotado foi o mesmo para ambos os casos.

O trabalho foi estruturado em 8 etapas, como apresentado na Figura 1, que são elas: a seleção das base de dados, a seleção e refinamento dos artigos, o fichamento e revisão bibliografica dos dados, coleta dos resultados, comparações com trabalhos de outros autores com mesma linha de pesquisa, e, formulação das conclusões.

Figura 1 - Fluxograma dos processos para formulação do trabalho

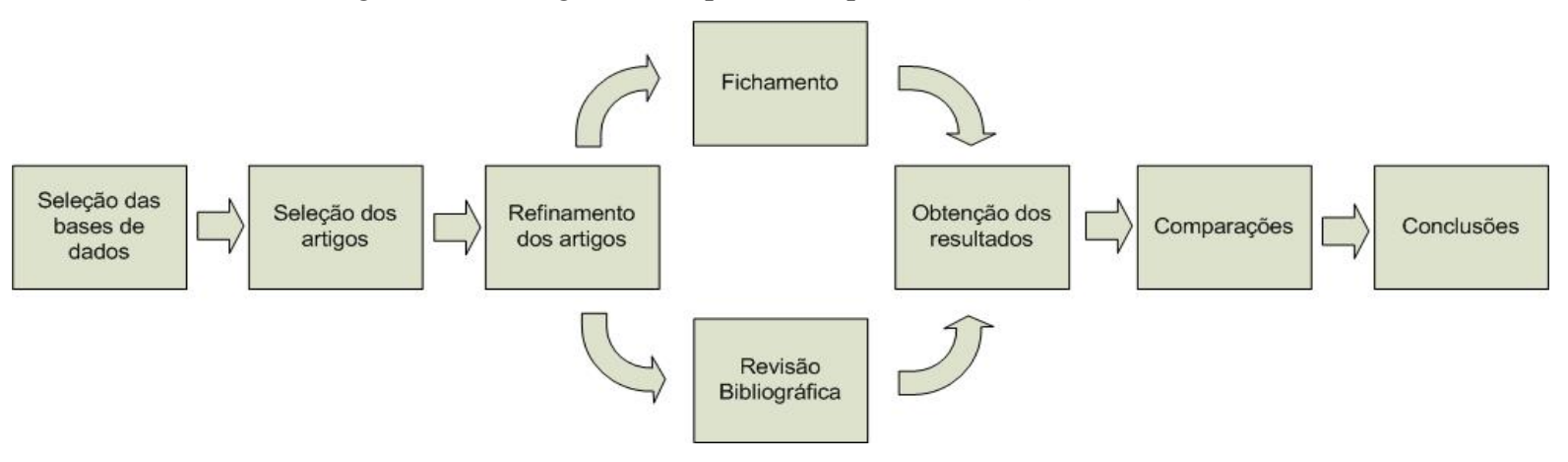

Fonte: Autoria Prórpia (2009) 
Dados os elementos constituintes do trabalhos, pode-se desenvolver os seus pressupostos teóricos.

\section{Modelos de gestão}

Na última década passaram a ser adotadas formas alternativas, mistos de conhecimentos existentes e novos modelos de gestão com diferentes concepções. Os novos modelos de gestão devem ser estudados e analisados, a fim de criar novas percepções da organização e sua gestão.

Embasados na evolução desses modelos organizacionais surgiram, e estão em constante evolução, os sistema de gestão do desempenho, e são assim descritos por Peixinho (2003):

- Gestão orientada por custos - Muito visada e apropriada para ambientes empresariais na sociedade industrial, valoriza apenas os ativos tangíveis, de forma que os indicadores refletem apenas o desempenho financeiro das organizações. Esse sistema trabalha de forma hierarquizada no estilo top-down, enfatiza o enfoque interno e tem como conceito-chave o valor agregado. Este modelo de contabilidade gerencial tornou-se inadequado devido ao ambiente dinâmico, complexo e de rápidas transformações dos dias atuais.

- Gestão orientada por resultado - Surgiu num ambiente de rápidas transformações tecnológicas e num mercado em crescente competitividade. Manter-se competitivo passou a ser um fator determinante para a sobrevivência da empresa. Sistemas de custo, de informações e de planejamento e controle da produção devem ser considerados de forma integrada (PEIXINHO, 2003 apud SOARES, 2003). Própria da sociedade da informação, a gestão orientada por resultados faz com que as empresas flexibilizem suas estratégias e, para assegurar sucesso, migrem de economia de escala para produto personalizado de qualidade. Com esta visão, além do custo, crescem em importância os fatores relacionados ao atendimento ao cliente, qualidade dos produtos e serviços, eliminação de desperdícios, prazo, otimização da produção e aperfeiçoamento contínuo para a obtenção de um melhor posicionamento estratégico da empresa.

- Gestão orientada para a estratégia - Este sistema parte da premissa de que na sociedade do conhecimento a vantagem competitiva deriva-se dos recursos intangíveis, como conhecimento, capacidade e relacionamento criados pelos empregados em contrapartida dos investimentos em ativos físicos e do acesso de capital. Além de incorporar princípios da TQM, este sistema visa abordagem focada na estratégia e sua implementação deve ser compartilhada por todos da organização. Esse tipo de gestão deve ser considerado um processo contínuo e liderado pela alta administração, pois além de preservar as mensurações 
de desempenho financeiro, complementa com indicadores de desempenho não-financeiros, emanados da visão e da estratégia da organização.

Sabe-se que os sistemas de mensuração de desempenho têm como objetivo principal a indução dos departamentos a fazerem o que é bom para a empresa como um todo e, por esse motivo, apóiam os modelos de gestão estratégica.

Por intermédio da concepção e evolução dos modelos que fundamentam os sistemas de medição de desempenho, pode-se traçar uma trajetória de expansão e desenvolvimento, em que o estágio atual de desenvolvimento de tais sistemas aponta para o projeto de soluções totalmente integradas. Tais sistemas compreendem soluções que ilustram algumas capacitações que foram desenvolvidas ao longo dos últimos quinze anos:

- A matriz de desempenho de Keegan et al. (1989) que desenvolve uma abordagem que integra aspectos 'internos' e 'externos', fatores 'financeiros' e 'não-financeiros'.

- O sistema SMART de Cross e Lynch (1989) que desenvolve uma técnica para integrar a medição, a análise e a geração de relatórios dentro de uma perspectiva estratégica. Estes autores trabalham com a hierarquia do desempenho (pirâmide de desempenho) para estabelecer relações de causa e efeito entre a 'visão' organizacional e as ações que se desenvolvem no nível operacional. Há uma clara gestão dos aspectos internos e externos que contribuem para o desenvolvimento de uma eficiência interna e de uma eficácia externa, no que se refere às ações desenvolvidas.

- O modelo de medição de desempenho proposto por Fitzgerald et al. (1991) integra os conceitos de determinantes e resultados no que se refere ao desempenho do sistema de operações, claramente explorando as causalidades entre os dois conceitos. As medidas de desempenho podem estar relacionadas a resultados (posição competitiva, desempenho financeiro), ou podem representar determinantes do desempenho (custo, qualidade, tempo, flexibilidade e inovação).

- O sistema integrado e dinâmico de medição de desempenho - IDPMS - concebido por Ghalayini et al. (1997) incorpora no sistema de medição de desempenho, propriedades relacionadas à dinâmica das operações e outras relativas integrações do sistema de gestão.

- As características dinâmicas do desempenho também são trabalhadas no 'prisma' de desempenho desenvolvido por Neely et al. (2000). O sistema desenvolvido é um scorecard para medir a gerenciar as relações com os stakeholders da organização.

Atualmente, a metodologia disponível e mais aceita no mercado é o Balanced Scorecard, desenvolvida por Kaplan e Norton (1997). Essa nova abordagem para administração estratégica foi bem aceita, pois além de preservar as medidas financeiras de desempenho, é complementada com medidas dos vetores que impulsionam o desempenho futuro, pois tais medidas derivam da visão e 
estratégia da empresa e é formada por quatro perspectivas: financeira, cliente, processos internos e, perspectivas de aprendizado e crescimento.

\section{Pesquisa, fichamento e dados}

A pesquisa nos anais do ENEGEP foi realizada através do site da Associação Brasileira de Engenharia de Produção (ABEPRO), que disponibiliza à comunidade artigos científicos apresentados nos Encontros Nacionais de Engenharia de Produção, e na base de dados Scielo, que apresenta artigos de periódicos nacionais. Tais bases foram escolhidas por terem padrões que são reconhecidos nacionalmente e internacionalmente pelos acadêmicos. Os artigos foram buscados a partir de apenas um critério em primeira instância, sendo a busca pelos seguintes termos: Medida de Desempenho, Medidas de Desempenho, Medição de Desempenho (Performance Measurement), Sistema de Medição de Desempenho (Performance Measurement System), Indicadores de Desempenho (Performance Indicator), Balanced Scorecard, Pirâmide de Desempenho (Performance Prism) e ABC. Posteriormente foi analisado cada artigo do banco de dados com intuito de excluir os que não estivessem meticulosamente relacionados ao tema. Ao final foram coletados na ABEPRO e no Scielo um total de 159 e 20 artigos respectivamente.

Seguidamente foi montado um formulário (Figura 2) onde constava cada variável a ser pesquisada, sendo as variáveis: ano de publicação, entidade de ensino e pesquisa a que o autor encontra-se vinculado, palavras-chave, citações e o tipo de publicação da citação (livro, revista, tese,...).

Figura 2 - Formulário

\begin{tabular}{|c|c|c|c|c|c|c|}
\hline & $\begin{array}{c}\text { Título do } \\
\text { Artigo }\end{array}$ & $\begin{array}{c}\text { Ano de } \\
\text { Publicação }\end{array}$ & $\begin{array}{c}\text { Instituição } \\
\text { Publicadora }\end{array}$ & $\begin{array}{c}\text { Palavras- } \\
\text { Chave }\end{array}$ & $\begin{array}{c}\text { Referências } \\
\text { Bibliográficas }\end{array}$ & $\begin{array}{c}\text { Tipo de } \\
\text { Publicação }\end{array}$ \\
\hline 1 & & & & & & \\
\hline 2 & & & & & & \\
\hline 3 & & & & & & \\
\hline
\end{tabular}

Fonte: Autoria Prórpia (2009)

Vale ressaltar que o campo 'Título do Artigo' fora usado apenas para que não houvesse duplicidade de artigos, comprometendo assim os resultados obtidos. 


\section{Resultados}

Com o banco de dados e os formulários devidamente preenchidos foram coletados dados relevantes que estarão detalhados nas próximas seções.

\subsection{Ano de publicação}

A primeira variável estudada foi os anos de publicação dos artigos. O gráfico 1 mostra a quantidade de artigos publicados em cada ano do ENEGEP assim como o Gráfico 2 mostra a quantidade de artigos publicados contidos na base de dados Scielo, ambos no período proposto.

Gráfico1 - Número de publicação por ano no ENEGEP.

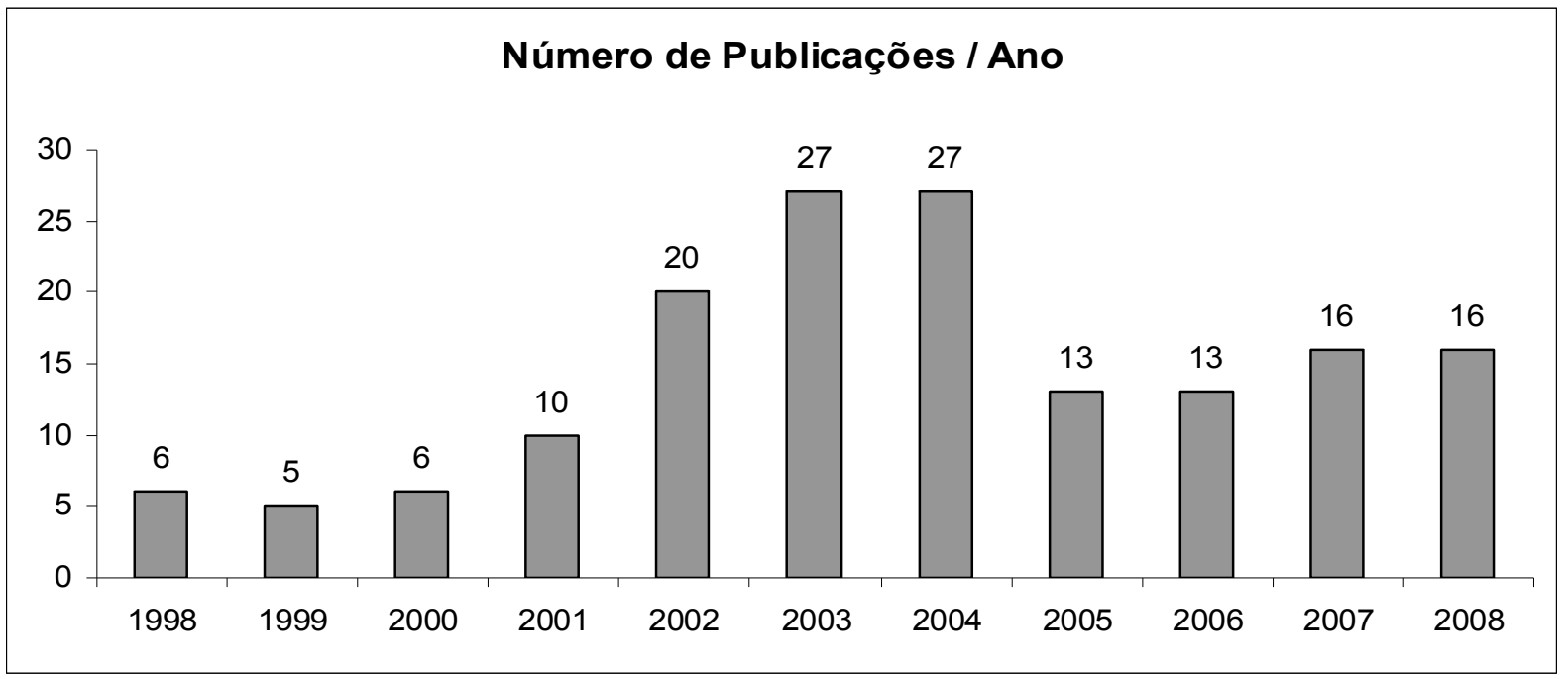

Fonte: Autoria Prórpia (2009)

Gráfico 2 - Número de publicação por ano na base Scielo.

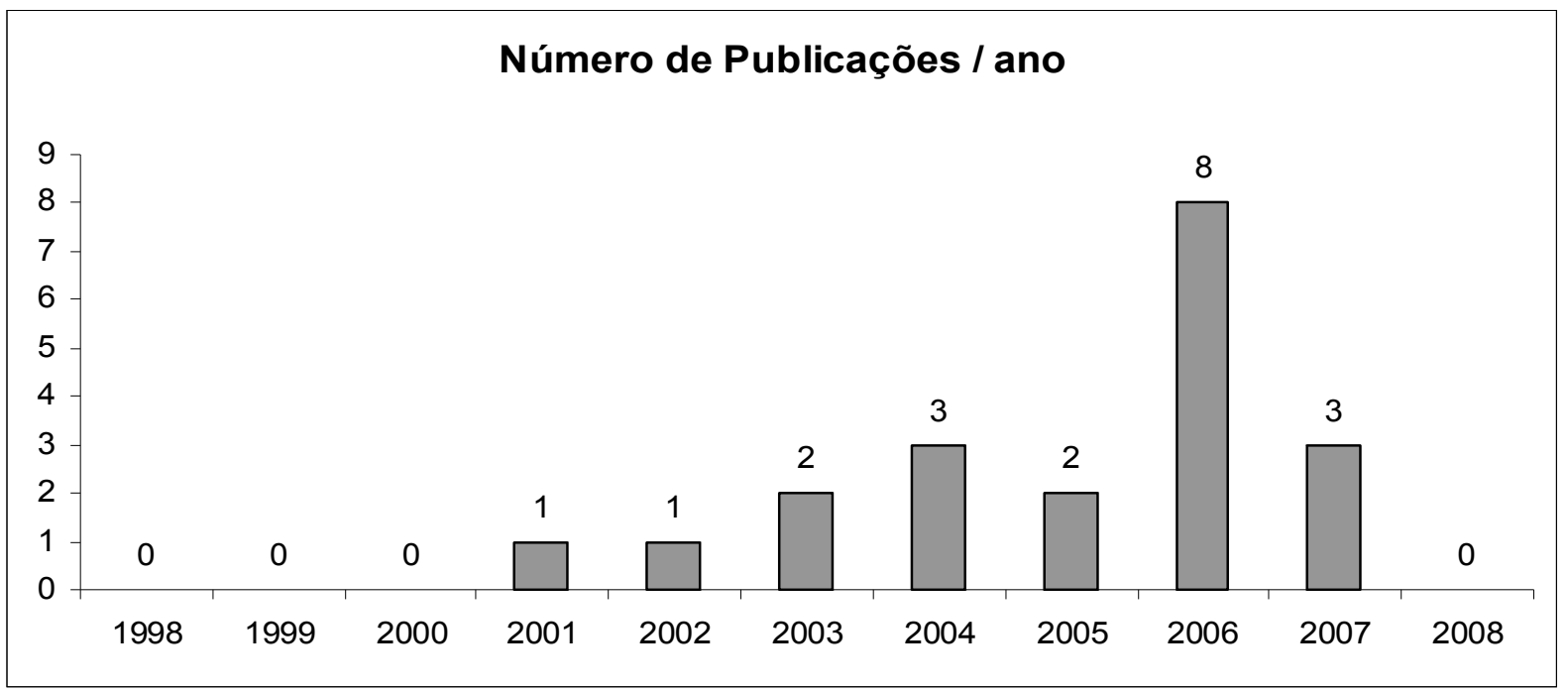

Fonte: Autoria Prórpia (2009) 
A partir destes dados vê-se que houve um crescimento no número de publicação no ENEGEP sobre o tema em questão a partir de 1999 e teve uma grande concentração de publicação no período 2002-2004 contendo 46,54\% da quantidade total. Os anos posteriores tiveram uma quantidade bem próxima de publicações.

Já a base de dados Scielo nos dá uma diferente posição, onde a maior concentração de publicações foi em 2006 onde houve 40\% delas e o período de maior publicação foi posterior ao do ENEGEP sendo de 2004 a 2007, somando um total de $80 \%$.

\subsection{Entidades de ensino e pesquisa}

A segunda variável estudada foi as entidades publicadoras em que o autor está vinculado, e a Tabela 1 mostra em ordem crescente as entidades que mais publicaram no período proposto referentes aos artigos buscados nos anais do ENEGEP e a Tabela 2 referentes aos artigos buscados na base de dados Scielo.

Vale ressaltar que, quando houve mais de um autor e/ou mais de uma entidade publicadora vinculada, foram consideradas ambas para contagem.

Na categoria "outras" estão inclusas todas as instituições, sejam elas públicas, particulares ou empresas, que obtiveram um montante de publicações menor ou igual a 5 artigos para o caso do ENEGEP e 1 artigo para o caso da base Scielo.

Tabela 1 - Número de Publicações por entidade referente ao ENEGEP

\begin{tabular}{cc}
\hline Entidade Publicadora & Número de Artigos \\
\hline UFF & 7 \\
UNESP & 7 \\
UFRJ & 8 \\
PUC-PR & 8 \\
UFRGS & 15 \\
UFSC & 16 \\
UFSCAR & 22 \\
USP & 26 \\
Outras & 71 \\
\hline
\end{tabular}

Fonte: Autoria Prórpia (2009)

Tabela 2 - Número de Publicações por entidade referente à base Scielo

\begin{tabular}{cc}
\hline Entidade Publicadora & Número de Artigos \\
\hline UFMG & 2 \\
UFRJ & 2 \\
UFSCAR & 2 \\
USP & 4 \\
Outras & 10 \\
\hline
\end{tabular}

Fonte: Autoria Prórpia (2009) 
A partir destes dados podemos verificar que a USP e a UFSCAR possuem a maior quantidade de artigos publicados no período analisado, correspondendo em ambos os casos a cerca de $30 \%$ do total de artigos coletados. Vê-se também que a grande maioria das publicações provém das instituições públicas de ensino, sendo no caso dos artigos provindos do ENEGEP e do Scielo um montante de $82,39 \%$ e $85 \%$ respectivamente.

Esses resultados são semelhantes aos apresentados por Ruy e Martins (2006), que desenvolveram um estudo com mesma linha de pesquisa e os resultados por eles obtidos foram que as entidades que mais publicam são a USP e a UFSCAR respondendo a 29,17\% do total.

\subsubsection{Publicações por estado}

A partir dos resultados obtidos no tópico anterior podemos analisar uma variável vinculada: a porcentagem de publicações por estado. O Gráfico 3 e Gráfico 4 nos mostrarão os estados que mais publicaram sobre o tema no período considerado.

Gráfico 3 - Porcentagem de publicações por estado dos artigos do ENEGEP

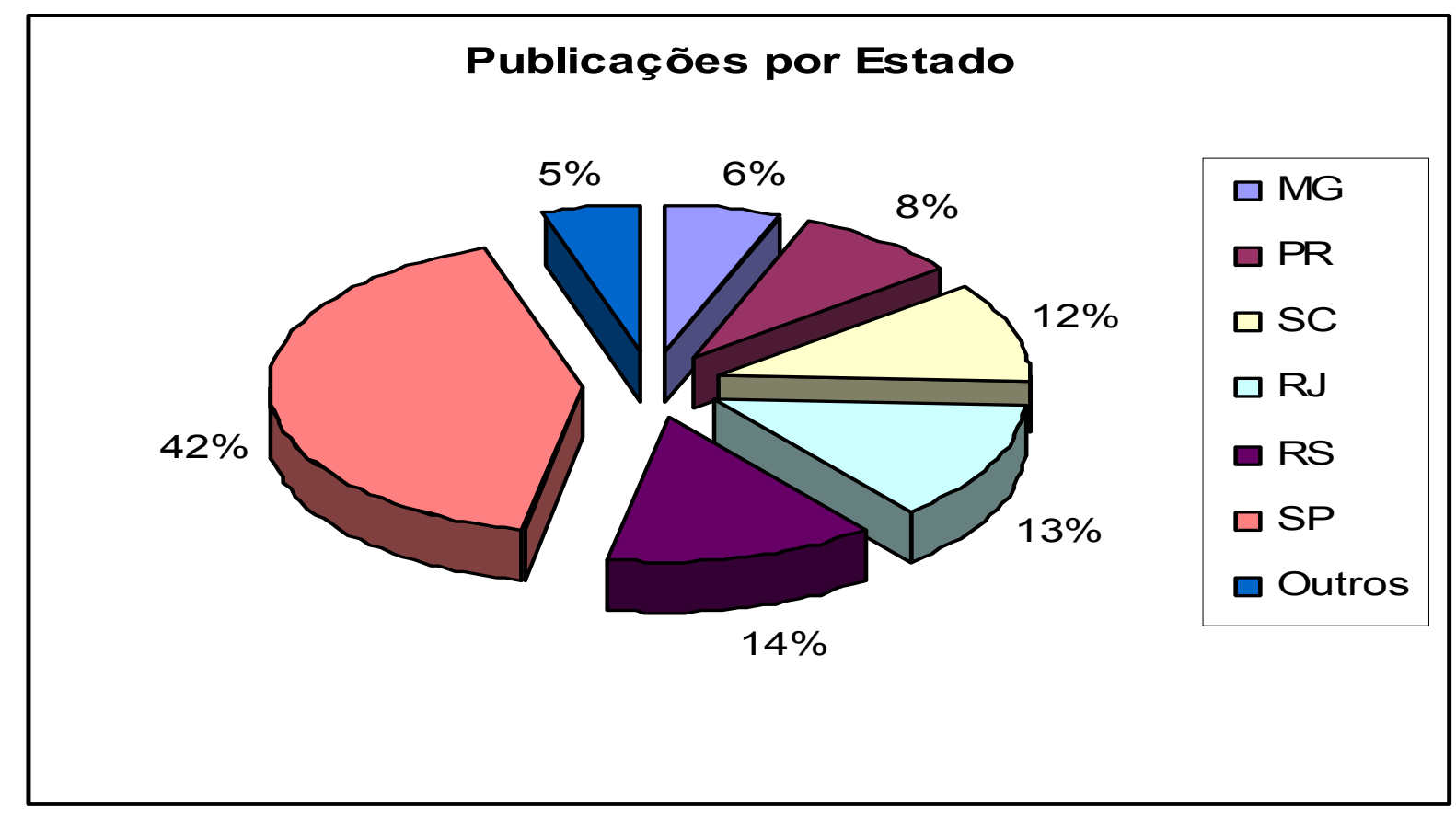

Fonte: Autoria Prórpia (2009) 
Gráfico 4 - Porcentagem de publicações por estado dos artigos da base Scielo

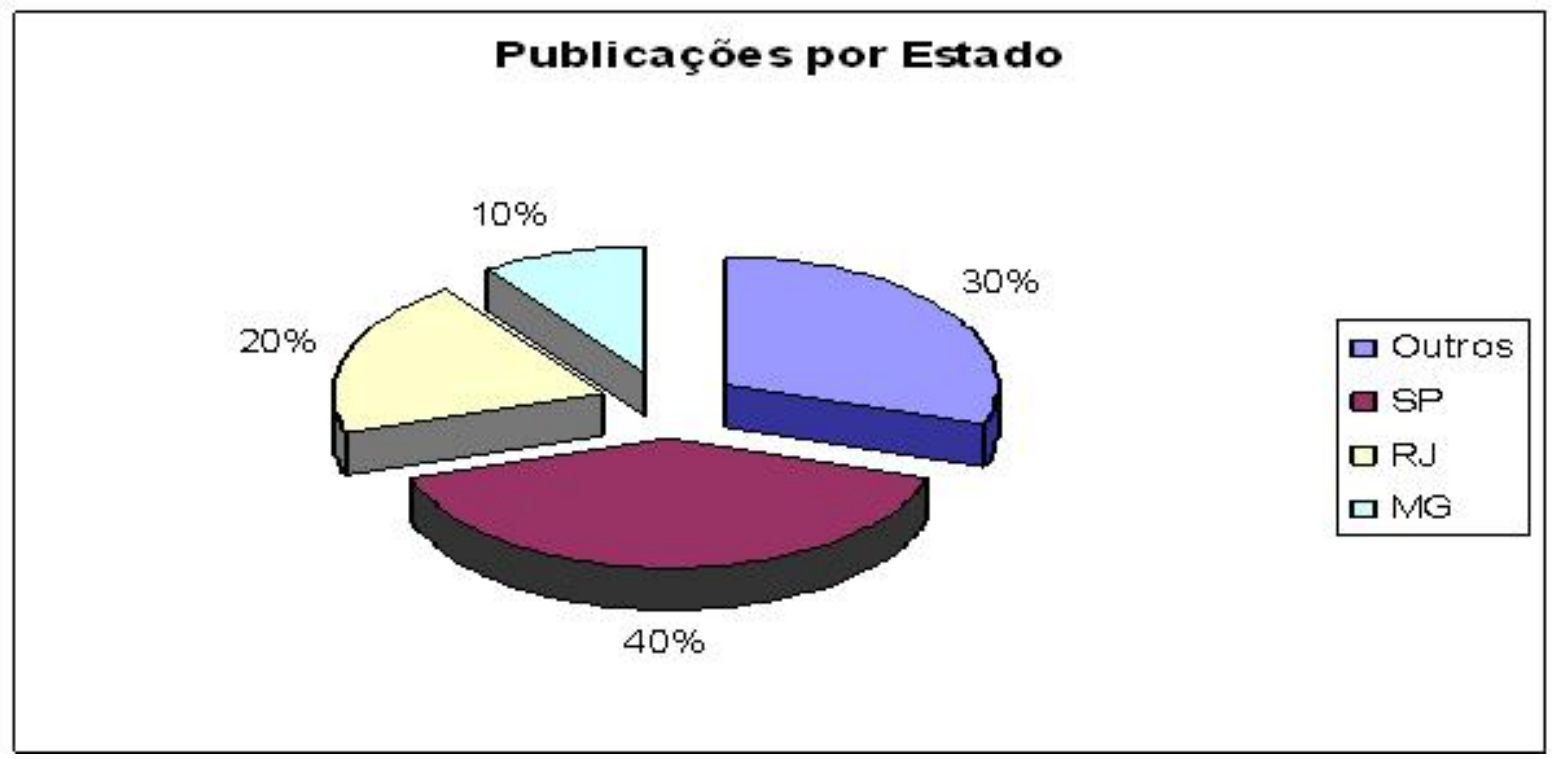

Fonte: Autoria Prórpia (2009)

Na categoria "Outros" estão classificados todos os estados que não atingiram porcentagem considerável, tendo menos de $5 \%$ do total. Vale ressaltar que essa categoria possui grande porcentagem no Gráfico 4 pois ocorreram casos de publicações de autores internacionais nos artigo retirados da base Scielo. Esse número é reduzido para $20 \%$ se consideradas somente as publicações brasileiras.

Nessa variável podemos observar a grande quantidade de publicações provindas de entidades paulistas, que em ambos os casos aparecem com cerca de $40 \%$ do total. O sudeste é responsável por $61 \%$ das publicações provindas do ENEGEP e 70\% das referentes a base Scielo e se a região considerada for expandida para Sul-Sudeste esse percentual aumenta para 94,94\% e $80 \%$ respectivamente.

Assim como na seção anterior, os resultados foram comparados ao estudo feito por Ruy e Martins (2003) e foram apresentados resultados semelhantes onde o estado de São Paulo aparece como maior publicador sobre o assunto com $47,22 \%$, o Sudeste correspondeu a $61,1 \%$ e o eixo SulSudeste a 94,4\% do total de publicações no período 2003 -2005 (período por eles analisado).

\subsection{Referências bibliográficas}

Foi coletado um total de 2722 referências bibliográficas dos artigos consultados do ENEGEP e 492 dos artigos consultados no Scielo. A partir desses dados foi possível analisar 3 variáveis: Tipo de publicação da citação, os livros mais citados e os autores mais citados. 


\subsubsection{Tipo de publicação da citação}

Com a análise dos dados foi encontrado 7 categorias distintas e assim foram divididas: livros, periódicos nacionais, periódicos internacionais, Tese/Dissertação/Monografia/TCC, relatórios, normas técnicas e artigos de eventos. Essa variável verificou o tipo da publicação e a proveniência das citações feitas nos artigos.

O Gráfico 5 e Gráfico 6 mostram as porcentagens de cada tipo de publicação provindas dos artigos obtidos do ENEGEP e da base Scielo respectivamente.

Gráfico 5 - Tipos de publicação das citações dos artigos provindos do ENEGEP

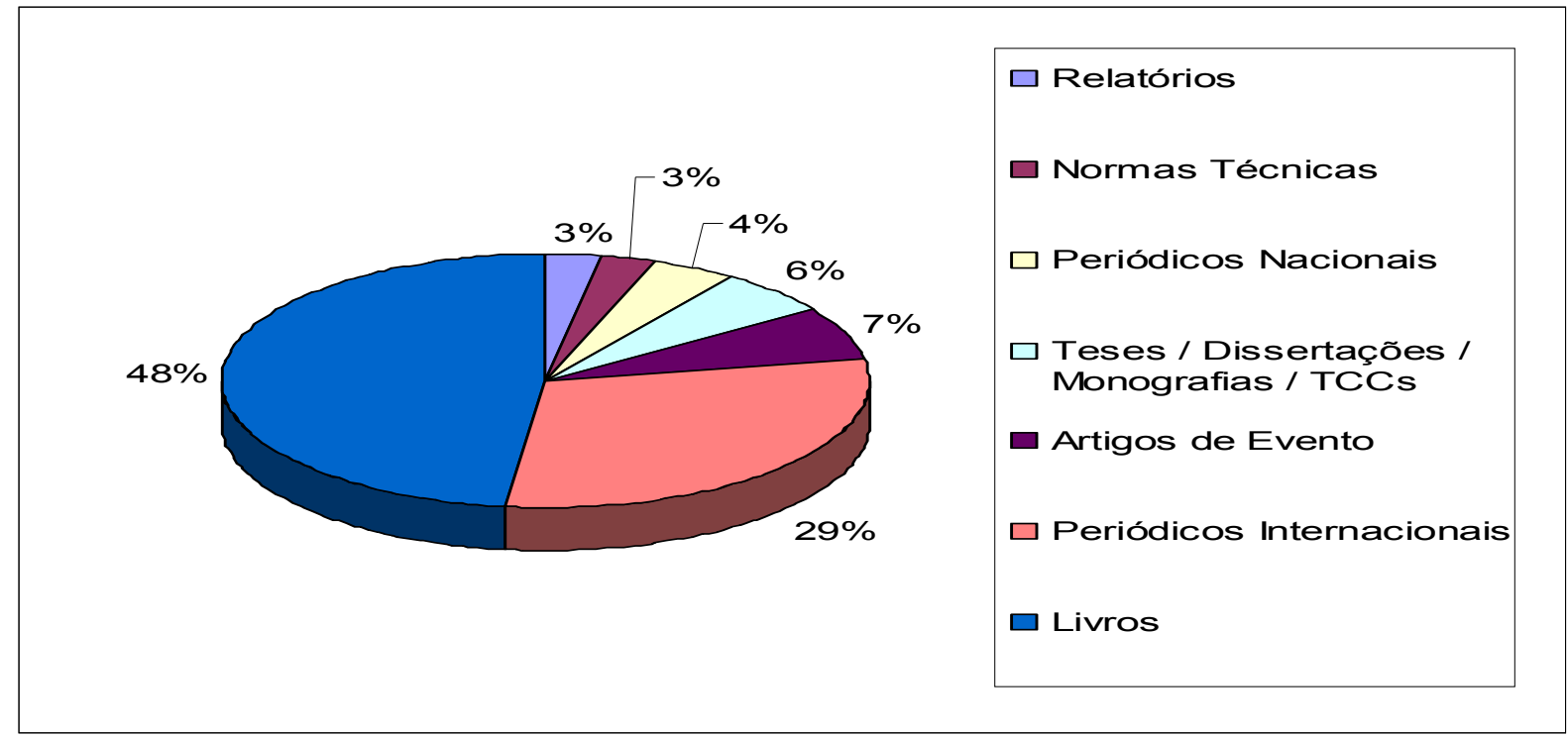

Fonte: Autoria Prórpia (2009)

Gráfico 6 - Tipos de publicação das citações dos artigos provindos do Scielo

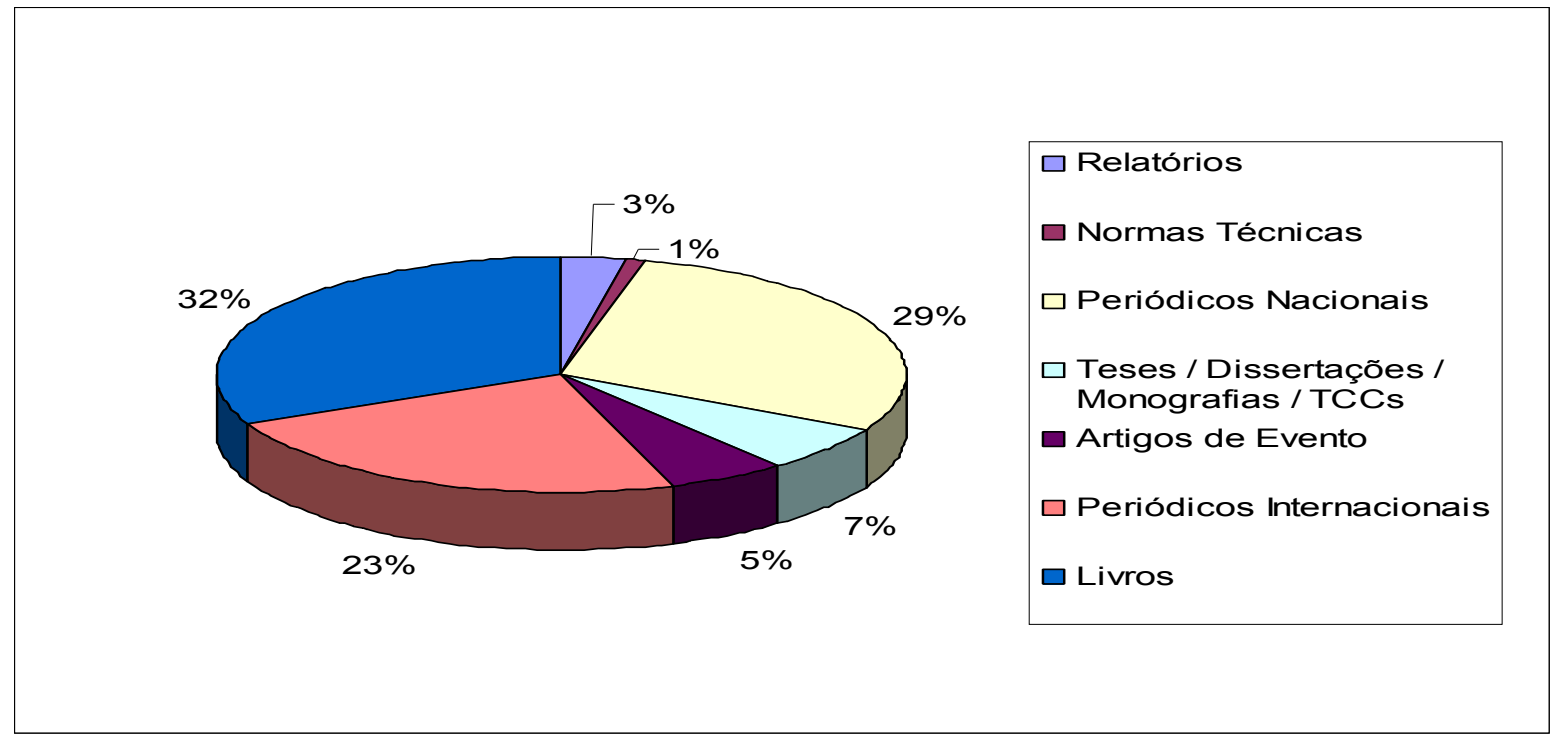

Fonte: Autoria Prórpia (2009)

Primeiramente, pode-se observar uma concentração forte de fontes bibliográficas provindas de livros, que é maioria em ambos os casos e em um deles corresponde a quase $50 \%$ do total. 
Artigos de periódicos internacionais aparecem como segunda maior fonte de bibliografia no caso do ENEGEP seguidamente de artigo de eventos, divergindo do caso da base Scielo onde os artigos publicados em periódicos nacionais aparecem em segundo lugar, seguido dos artigos publicados em periódicos internacionais.

\subsubsection{Livros mais citados}

A Tabela 3 e Tabela 4 descrevem em ordem decrescente o nome, autor, ano de publicação e o número de citações dos livros que mais aparecem nos artigos provindos do ENEGEP e da base Scielo respectivamente.

Tabela 3 - Livros mais citados nos artigos provindos do ENEGEP

\begin{tabular}{|c|c|c|c|}
\hline Livro & Autor (es) & Ano de Publicação & $\mathrm{N}^{\circ}$ de Citações \\
\hline A estratégia em ação: Balanced Scorecard & $\begin{array}{l}\text { KAPLAN, Robert. S., } \\
\text { NORTON, David P. }\end{array}$ & 1997 & 98 \\
\hline Organização Orientada para a Estratégia & $\begin{array}{l}\text { KAPLAN, Robert. S., } \\
\text { NORTON, David P. }\end{array}$ & 2001 & 47 \\
\hline $\begin{array}{c}\text { Perspectives on Performance: The } \\
\text { Performance Prism }\end{array}$ & $\begin{array}{l}\text { NEELY, A. e ADAMS, } \\
\text { C. }\end{array}$ & 2001 & 21 \\
\hline Estudo de caso: planejamento e métodos & YIN, Robert K. & 2001 & 21 \\
\hline Measuring Business Performance & NEELY, A & 1998 & 18 \\
\hline Sinais Vitais & Hronec, S. M & 1994 & 17 \\
\hline Condutores da Performance & $\begin{array}{l}\text { OLVE, N.G., ROY,J. e } \\
\text { WETTER, M. }\end{array}$ & 2001 & 17 \\
\hline Vantagem competitiva & PORTER, Michael E. & 1989 & 17 \\
\hline Administração da produção & SLACK, Nigel & 1997 & 15 \\
\hline $\begin{array}{l}\text { Planejamento e medição para a } \\
\text { performance }\end{array}$ & $\begin{array}{c}\text { SINK, D. S.; TUTTLE, T. } \\
\text { C. }\end{array}$ & 1993 & 14 \\
\hline
\end{tabular}

Fonte: Autoria Prórpia (2009)

Tabela 4 - Livros mais citados nos artigos provindos Do Scielo

\begin{tabular}{|c|c|c|c|}
\hline Livro & Autor(es) & Ano de Publicação & $\mathbf{N}^{0}$ de Citações \\
\hline A estratégia em ação: Balanced Scorecard & $\begin{array}{l}\text { KAPLAN, Robert. S., } \\
\text { NORTON, David P. }\end{array}$ & 1997 & 6 \\
\hline Vantagem competitiva & PORTER, Michael E. & 1989 & 4 \\
\hline Administração da produção & SLACK, Nigel & 1997 & 3 \\
\hline $\begin{array}{l}\text { Estratégia competitiva: técnicas para análise } \\
\text { de indústrias e concorrência }\end{array}$ & PORTER, Michael E. & 1997 & 3 \\
\hline $\begin{array}{c}\text { Perspectives on Performance: The } \\
\text { Performance Prism }\end{array}$ & $\begin{array}{l}\text { NEELY, A. e ADAMS, } \\
\text { C. }\end{array}$ & 2001 & 3 \\
\hline Estudo de caso: planejamento e métodos & YIN, Robert K. & 2001 & 2 \\
\hline Sinais Vitais & Hronec, S. M & 1994 & 2 \\
\hline Organização Orientada para a Estratégia & $\begin{array}{l}\text { KAPLAN, Robert. S., } \\
\text { NORTON, David P. }\end{array}$ & 2001 & 2 \\
\hline
\end{tabular}




\begin{tabular}{cccc} 
Condutores da Performance & OLVE, N.G., ROY,J. e & 2001 & 2 \\
Measuring Business Performance & WETTER, M. & 1998 & 2 \\
\hline
\end{tabular}

Fonte: Autoria Prórpia (2009)

Frente a esses dados pode-se observar vários pontos importantes:

- Há uma grande similaridade entre os livros buscados quando o tema se trata de medição de desempenho. Observa-se que 9 entre os 10 livros listados em cada tabela aparecem em ambas.

- $\quad$ O livro mais citado foi "A estratégia em ação: Balanced Scorecard” de Kaplan e Norton. Esse resultado não causa muita surpresa, pois atualmente o BSC é a principal metodologia de gestão disponível e aceita no mercado, onde no começo era apenas um modelo de avaliação e performance empresarial, porém, sua implantação e aprimoramento nas empresas tornou-o uma metodologia de gestão estratégica e, para Campos (1998), a sigla BSC (Balanced Scorecard) pode ser traduzida para Cenário balanceado, ou ainda para Indicadores Balanceados de Desempenho, isso se dá ao fato de uma organização não se restringir unicamente ao foco econômico financeiro, utilizando também de ativos intangíveis.

- $\quad$ O BSC foi escolhido pela renomada revista Harvard Business Review como uma das práticas de gestão mais importantes e revolucionárias dos últimos 75 anos (BOURNE, et al., 2005) e pesquisas recentes indicam que 50\% das empresas da lista Fortune, 1000 estão utilizando o BSC nos Estados Unidos, e na Europa entre 40\% e 45\% (LIMA, 2004), além de ser uma prática de gestão que contribui diretamente para o atendimento dos critérios de excelência do PNQ.

- $\quad$ Robert Kaplan, David Norton, Andy Neely e Michael Porter possuem 2 livros cada nas listas apresentadas, isso também não resulta em grande surpresa uma vez que são eles que protagonizam a lista de autores mais citados, que será apresentado a seguir.

\subsubsection{Autores}

Os Gráficos 7 e 8 listam os autores mais citados e a quantidade de vezes em que foram citados nos artigos consultados do ENEGEP e da base Scielo. 
Gráfico 7 - Autores mais citados nos artigos consultados do ENEGEP

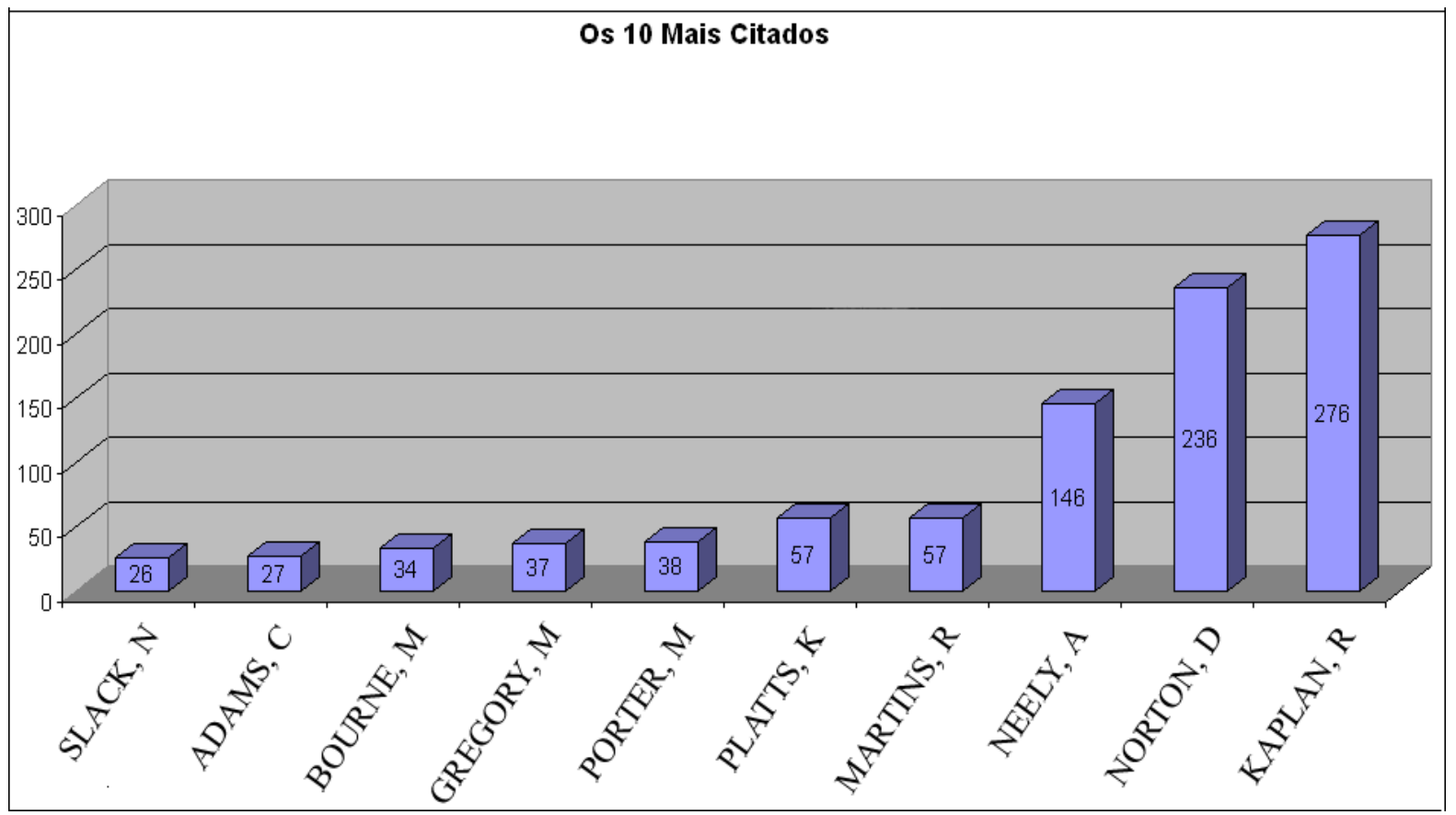

Fonte: Autoria Prórpia (2009)

Gráfico 8 - Autores mais citados nos artigos consultados no Scielo

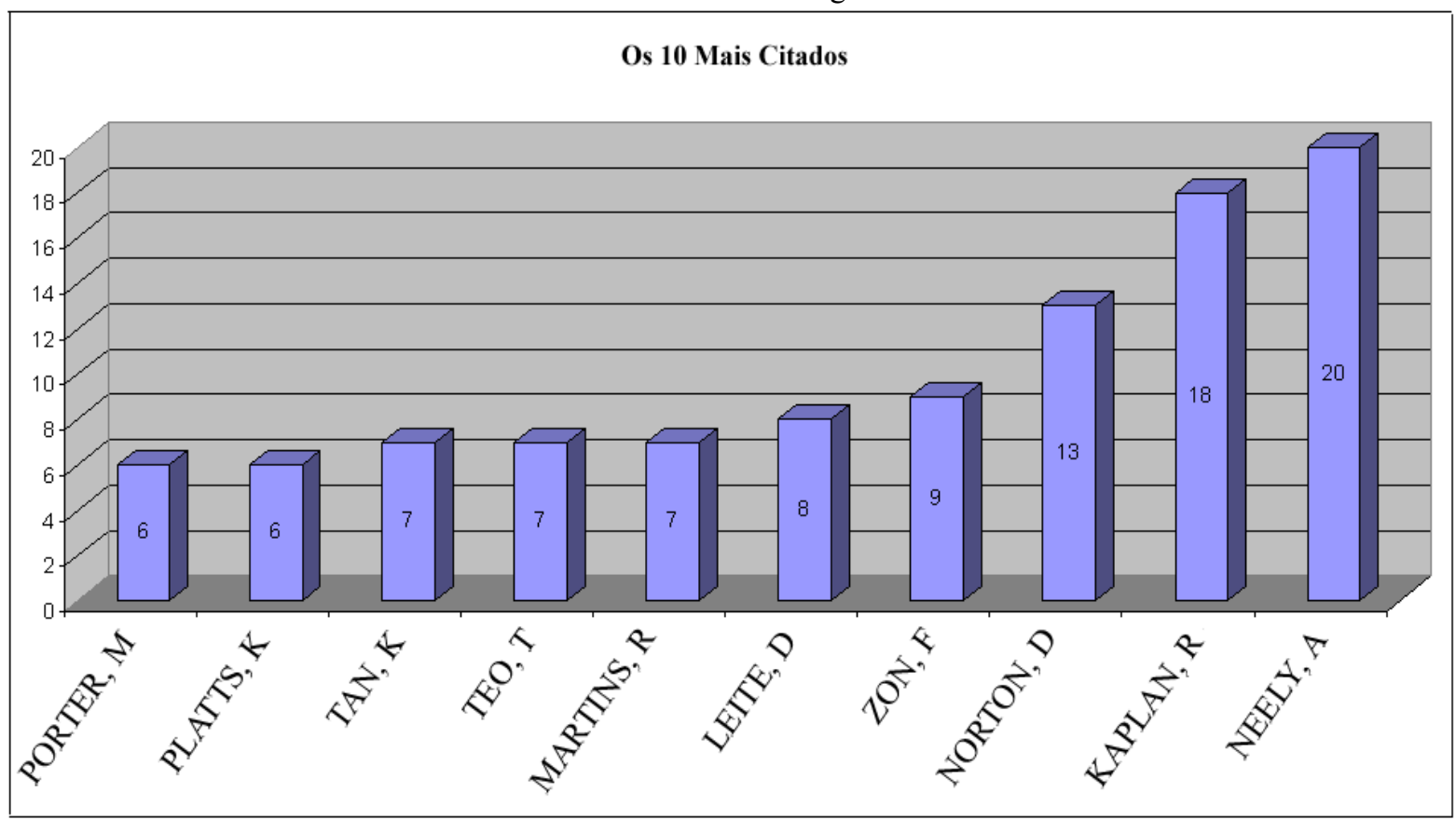

Fonte: Autoria Prórpia (2009)

O artigo de Marr e Schiuma (2003) possui a mesma linha de pesquisa deste artigo e nele foi realizado um estudo que possui como um dos resultados uma lista com os autores mais citados no período de 1998 a 2002 quando o tema em questão é medição de desempenho e apontou os mais 
citados sendo (em ordem decrescente): Kaplan, R.; Norton, D.; Neely, A.; Gregory, M.; Platts, K.; Eccles, R..

Podemos verificar que há uma grande convergência de informações entre os 3 casos. Verifica-se que Kaplan, Norton e Neely nos três casos aparecem no topo das listas, fortificando os dados obtidos na seção anterior onde cada um desses autores possuíam 2 livros na lista entre os 10 mais citados. Observa-se que Platts também aparece nas 3 listas, e Gregory, Porter e Martins aparecem em duas delas.

\subsubsection{Periódicos}

O Gráfico 9 e Gráfico 10 fazem referência aos periódicos acadêmicos mais citados nos artigos consultados do ENEGEP e da base Scielo respectivamente. Também está incluso nos gráficos o número de vezes em que cada um deles aparece nas referências bibliográficas.

Vale ressaltar que na categoria "outros" estão inclusos todos os periódicos que obtiveram menos de 10 e 2 citações, respectivamente para o Gráfico 9 e Gráfico 10.

Gráfico 9 - Número de Citações por periódico dos artigos consultados do ENEGEP

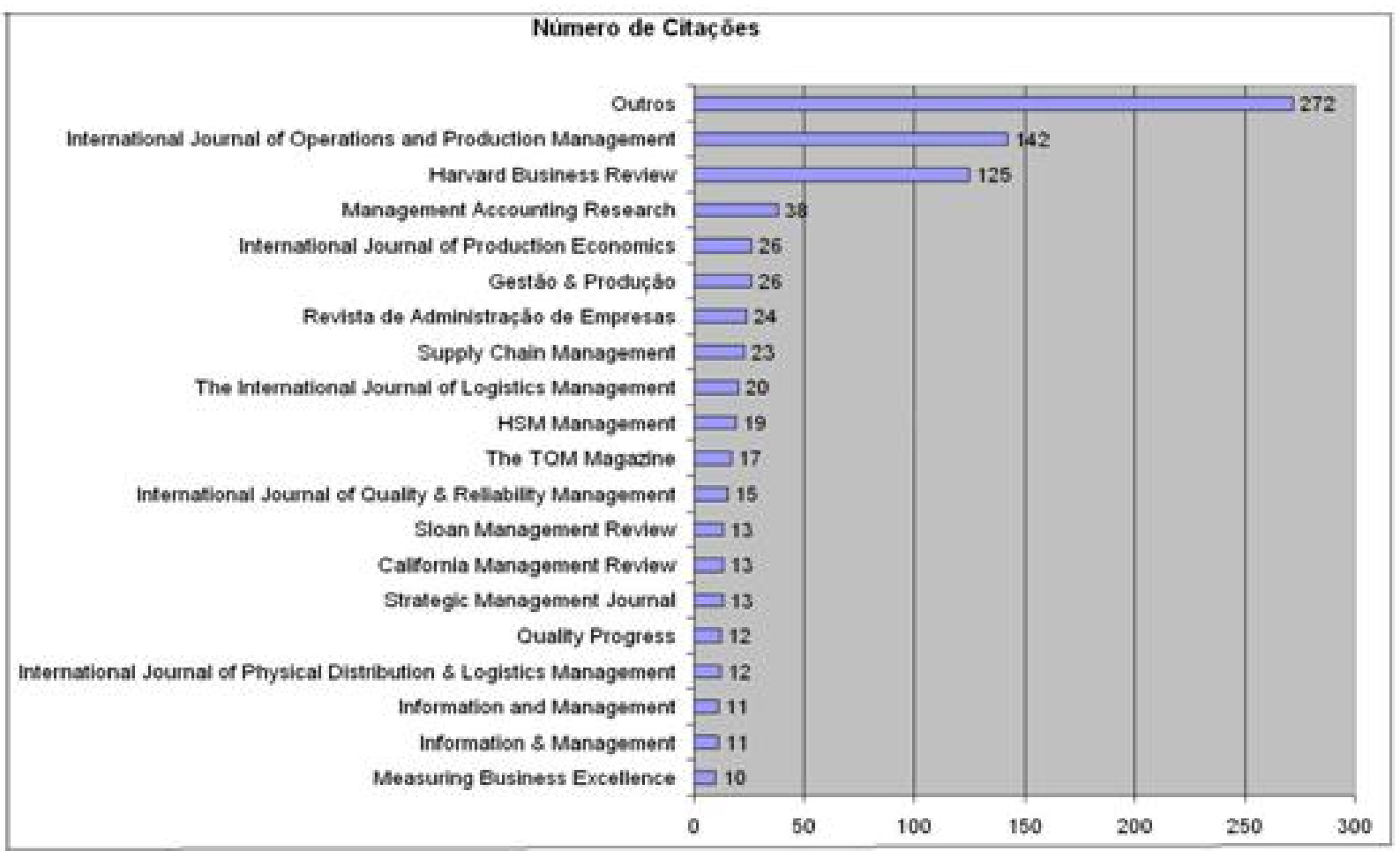

Fonte: Autoria Prórpia (2009) 


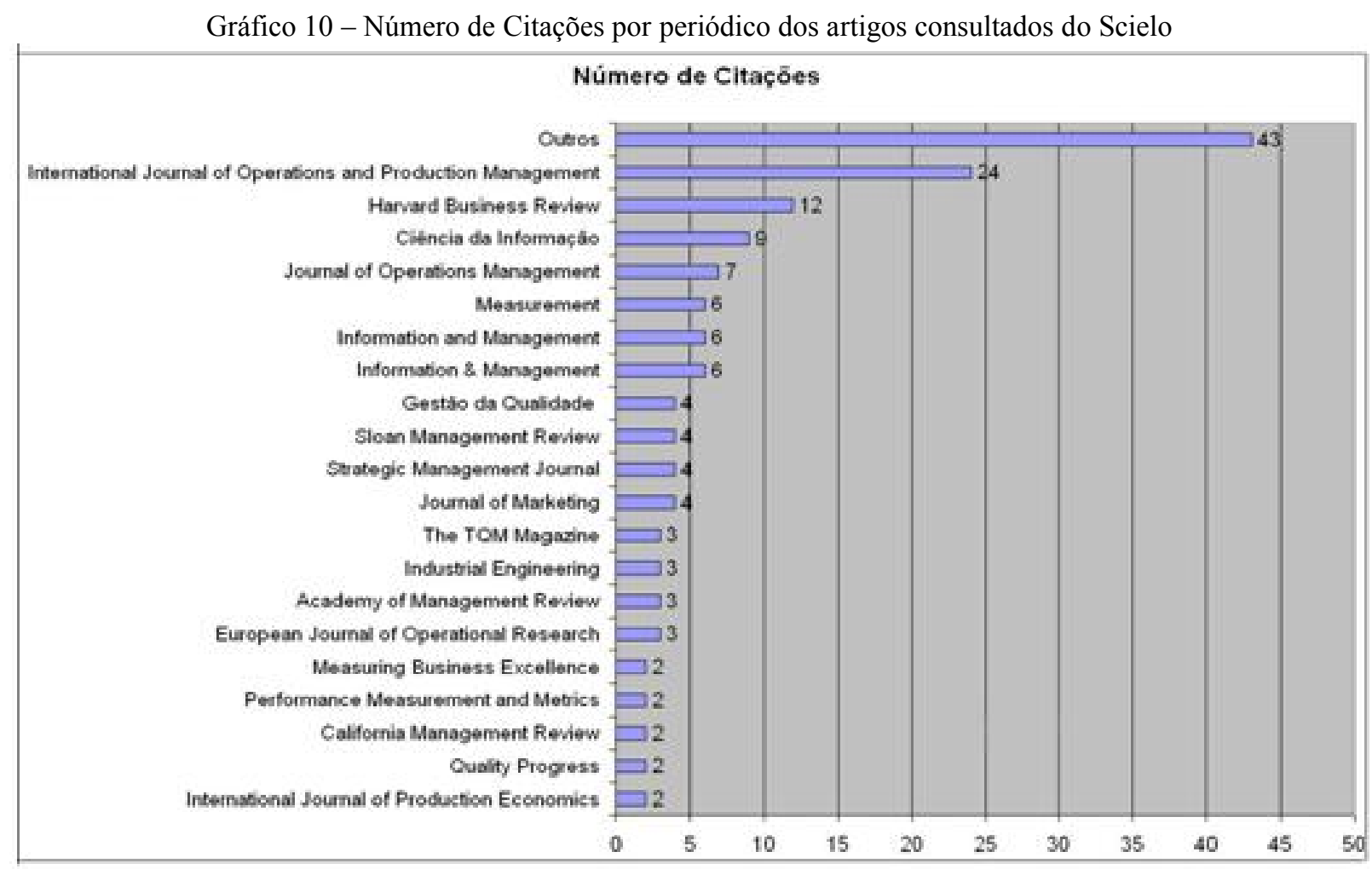

Fonte: Autoria Prórpia (2009)

Assim como no tópico anterior, os resultados aqui obtidos foram comparados aos obtidos no artigo de Marr e Schiuma (2003) onde também fora avaliada a variável "Periódicos mais citados". O resultado obtido pelos autores é apresentado em ordem decrescente na lista a seguir: Harvard Business Review; International Journal of Operations and Production Management; Journal of Marketing; Management Accounting Research; Strategic Management Journal; Sloan Management Review; Management Science; Academy of Management Journal; Accounting, Organization, and Society; Academy of Management Review.

Nelly (2005), também publicou um artigo com mesma linha de pesquisa e apontou que os periódicos mais citados são: Harvard Business Review, The International Journal of Operations \& Production Management e The Journal of the American Medical Association.

Também pode-se observar nesse caso uma grande convergência de informações. Nas 4 listas Harvard Business Review e Int. J. Operations and Production Management aparecem no topo como as mais citadas, com a diferença que a Harvard Business Review aparece em primeiro nos estudos de Marr e Schiuma (2003) e Nelly (2005). Também observa-se que o Strategic Management Journal e a Sloan Management Review aparecem em 3 das listas.

\subsection{Palavras-chave}


Palavra-chave é o termo que representa o conteúdo do texto e é elemento obrigatório em artigos de publicação periódica, com no mínimo 3 e no máximo 6 palavras.

Nessa variável foram verificadas e contabilizadas todas as palavras-chaves apresentadas nos artigos estudados e chegou-se às seguintes listas que estão apresentadas em ordem decrescente.

Tabela 5 - Número de artigos que possui tais palavras-chave nos artigos consultados do ENEGEP

\begin{tabular}{cc}
\hline Palavras-Chave & $\mathbf{n}^{\mathbf{0}}$ de citações \\
\hline Balanced Scorecard & 64 \\
Medição de Desempenho & 48 \\
Indicadores de Desempenho & 40 \\
Estratégia & 32 \\
Sistemas de Medição de Desempenho & 14 \\
Planejamento & 13 \\
Gestão Estratégica & 12 \\
Planejamento Estratégico & 10 \\
Cadeia de Suprimentos & 10 \\
Qualidade & 9 \\
\hline
\end{tabular}

Fonte: Autoria Prórpia (2009)

Tabela 6 - Número de artigos que possui tais palavras-chave nos artigos consultados no Scielo

\begin{tabular}{cc}
\hline Palavras-Chave & $\mathbf{n}^{\mathbf{0}}$ de citações \\
\hline Indicadores de Desempenho & 10 \\
Medição de Desempenho & 5 \\
Balanced Scorecard & 4 \\
Qualidade & 3 \\
Estratégia & 2 \\
Planejamento & 2 \\
Avaliação de Desempenho & 2 \\
Melhoria Contínua & 2 \\
Gestão da Qualidade & 2 \\
Gestão do Conhecimento & 2 \\
\hline
\end{tabular}

Fonte: Autoria Prórpia (2009)

Não causa surpresa as 3 palavras-chaves mais utilizadas nos artigos consultados. Medição de desempenho por ser um termo genérico que engloba vários temas como os sistemas de medição de desempenho, os indicadores de desempenho, entre outros; Os indicadores de desempenho por ser um tópico multidisciplinar, com diversas interfaces com outras áreas temáticas da Engenharia de Produção (RUY; MARTINS, 2006); e finalmente o Balanced Scorecard (BSC), pois como já supracitado é a metodologia de gestão atualmente mais aceita no mercado. Qualidade, Estratégia e Planejamento são outras palavras-chave utilizadas constantemente nos artigos e constam nas duas listas apresentadas. Isso se dá ao fato da medição de desempenho poder contribuir ao processo estratégico da empresa; a qualidade por outro lado é um dos elementos conquistados pelo desempenho; e para Martins (2000), um dos principais propósitos para o uso de sistemas de 
medição de desempenho é o planejamento, explicando assim o uso de tais palavras-chaves relacionadas ao tema em questão.

\section{Análise dos modelos de gestão}

Verifica-se nos estudos sobre sistemas de medição de desempenho e modelos de gestão a existência de uma excessiva concentração de publicações a respeito do BSC, principalmente tratando-se de estudos de caso sobre sua aplicação.

Modelos de gestão estudados e analisados por Martins (1999), como estando entre os mais relevantes, são raras vezes apresentados e há pouca abordagem sobre eles apesar de serem soluções oportunas frente aos tipos de preocupações estratégicas com que as organizações se deparam. Entre os analisados estão: SMART Performance Pyramid, modelo que ilustra a principal relação entre objetivos estratégicos, que são baseados nas necessidades dos consumidores e metas financeiras e de mercado, que são incrementados com medidas de satisfação dos consumidores, flexibilidade e produtividade, além de separar medidas de desempenho do ambiente interno e externo da empresa (CROSS; LYNCH, 1990); Sistema de Medição de Desempenho Integrado, que é baseado na integração da organização através do sistema de informação da empresa, além de ser um modelo sistêmico que prevê uma rede de informações que preserve a integridade das medidas de desempenho da empresa, integrados a um modelo de referência desenvolvido para integrar todas as mensurações, afim de serem planejadas e auditadas (BITITCI et al, 1997); e Performance Prism, modelo tridimensional que possui cinco fases, onde define-se primeiramente a estratégia, a partir disso define-se quais processos são necessários para alcançar a estratégia e qual a capacidade que a organização necessita em termos de recursos humanos, tecnologia e instalações para executar os processos, e por fim é definido como os acionistas podem contribuir para o desenvolvimento da capacidade e melhoria da empresa (NEELY et al, 2000).

Esperava-se também encontrar estudos sobre modelos híbridos que estão ganhando força no cenário atual devido aos bons resultados apresentados. Um exemplo é o Lean Six Sigma que segundo Adams (2003), os modelos Lean Manufacturing e o Six Sigma se forem bem aplicados, resultam em ótimos resultados para os negócios no longo prazo, pois o seu uso é uma simbiose lógica onde as duas partes possuem virtudes que se complementam, aumentando a qualidade, reduzindo tempos de ciclo e criando valor aos shareholders em todas as áreas da organização.

Outro exemplo é resultado de um estudo feito por Moullin (2004) onde houve a conclusão em seu trabalho que o envolvimento entre estratégias, processos, medidas e stakeholders não é encontrado em outro sistema de medição de desempenho, senão o Performance Prism, que complementa o Balanced Scorecard ao fazer a análise dos usuários finais, fornecedores, 
empregados e comunidade local, reforçando a tese de que os stakeholders podem ter um grande impacto na organização e na condução de suas atividades, pois da forma concebida o BSC cria um valor maior para os acionistas, já o Performance Prism para os stakeholders.

Porém, na amostra de artigos revisados nada foi encontrado sobre modelos híbridos e fica aqui demonstrada a carência de estudos nesta área e a sugestão para trabalhos futuros. Nesta linha de raciocínio, também encontram-se os modelos de gestão que fundamentam os prêmios da qualidade como o PNQ, EFQM, Malcom Baldrige, Deming, entre outros.

\section{Considerações finais}

Pôde-se perceber que a preocupação com os temas medição de desempenho e modelos de gestão vêm aumentando e sendo difundida nos últimos anos motivada pela necessidade das empresas de mensurar e controlar seus recursos eficientemente em busca da excelência e alinhado ao objetivo, esse trabalho analisou a produção acadêmica brasileira em Engenharia de Produção sobre o tema medição de desempenho e seus derivados no período de 1998 a 2008.

Primeiramente foi observada uma irregularidade de proporção quanto ao número de publicações em cada ano, havendo relevante concentração em determinados períodos.

Em segunda instância, foi observada, referente às entidades de ensino em que os autores estavam vinculados, uma desproporcionalidade, onde em grande maioria esse vínculo é mantido com instituições públicas de ensino, sendo a Universidade de São Paulo e a Universidade Federal de São Carlos destaques pela quantidade de artigos publicados, além disso, são estas pertencentes ao contexto de universidades presentes no estado de São Paulo, que se destaca fortemente como o estado com maior número de publicações.

Pode-se fazer a mesma observação quanto ao excessivo número de artigos, como já supracitado, que tem como abordagem central o Balanced Scorecard, desenvolvido por Kaplan e Norton (1997) e considerado uma das mais importantes práticas de gestão. Mas apesar desta consideração, verifica-se a necessidade de mais estudos sobre outros modelos e práticas de gestão que podem ser oportunas em determinadas organizações.

Porém, quando analisada as referências bibliográficas foi observada regularidade nos resultados obtidos quanto aos livros, autores e periódicos mais citados. Tais resultados obtidos foram comparados aos trabalhos de Marr e Schiuma (2003), Nelly (2005) e Ruy e Martins (2006), que possuíam mesma linha de pesquisa, e pôde-se observar grande convergência nos resultados, dando credibilidade aos resultados e conclusões aqui apresentadas.

Verificou-se o BSC, medição de desempenho e indicadores de desempenho como as palavras-chaves mais abordadas. O BSC, como já citado, por ser a prática de gestão mais aceita 
atualmente, medição de desempenho por ser um termo genérico que engloba vários temas e indicadores de desempenho, pois de acordo com Takashina e Flores (1996) eles são essenciais ao planejamento e controle dos processos das organizações, possibilitando o estabelecimento de metas e o seu desdobramento, pois são fundamentais esses resultados para a análise crítica dos desempenhos, para a tomada de decisões e para o novo ciclo de planejamento.

Apesar de suas limitações, como o número reduzido de artigos coletados na base Scielo em relação aos coletados do ENEGEP, esse trabalho deixa contribuições importantes, principalmente para estudos futuros na área de medição de desempenho que pode utilizar-se de idéias e resultados aqui apresentados para adquirir maior confiabilidade no processo de pesquisa e revisão bibliográfica.

\begin{abstract}
There is an increasingly demand for developing management models aligned to organizational strategy to achieve operations integration and flexibility, in order to face a global and dynamic business environment. This article aims to analyze the Brazilian Industrial Engineering academic production on performance measurement and management models themes in the period 1998 to 2008. A bibliographic survey data were analyzed, including factors as time publishing indexes, educational and research institutions, references and citations, authors and keywords. Data were recovered from ENEGEP proceedings and Scielo database. The results were compared to previous works developed by Marr e Schiuma (2003), Nelly (2005) and Ruy e Martins (2006). The results show a considerable convergence between the findings, as could be seen as a strong presence balanced scorecard models proposed by Kaplan and Norton (1996).
\end{abstract}

Key-words: bibliographic survey, ENEGEP, Scielo, performance measurement, management models.

\title{
Referências
}

ADAMS, M. Lean Six Sigma: A Tools Guide. Air Academy Associates, 2003.

BITITCI, U. S. Integrated performance measurement systems. International Journal of Operations \& Production Management. v 17, n.5, p.522-534, 1997.

cross ref

BOURNE, M. Researching performance measurement system implementation: the dynamics of success and failure. Production, Planning \& Control, v.16, n.2, p.101-113, 2005.

cross'

CAMPOS, J. A. Cenário Balanceado: painel de indicadores para a gestão estratégica dos negócios. São Paulo: Aquariana, 1998.

CORRÊA, H. L.; CORRÊA, C. A. Administração de produção e operações: manufatura e serviços: uma abordagem estratégica. São Paulo: Atlas, 2004.

COSTA, D. B.; FORMOSO, C. T.; LANTELME, E. M. Critérios para desenvolvimento de sistemas de indicadores de desempenho vinculados aos objetivos estratégicos de empresas da construção civil. Anais do XXII ENEGEP. Curitiba, 2002 .

CROSS, K. F.; LYNCH, R. L. Managing the corporate warriors. Quality Progress. v..23, n..4, p.54-59, 1990.

FITZGERALD, L.; JOHNSTON, R.; BRIGNALL, S.; SILVESTRO, R.; VOSS, C. Performance Measurement in Service Business. London: CIMA, 1991. 
GHALAYINI, A. M.; NOBLE, J. S.; CROWE, T. J. An integrated dynamic performance measurement system for improving manufacturing competitiveness. International Journal of Production Economics, v.48, n.3, p.207-225, 1997.

cross ${ }^{\text {ref }}$

HRONEC, S. M. Sinais vitais. São Paulo: Makron Books, 1994.

KAPLAN, R. S.; NORTON, D. P. Organização orientada para a estratégia: como as empresas que adotam o balanced scorecard prosperam no novo ambiente de negócios. 11 ed. Rio de Janeiro: Campus, 2001.

KAPLAN, R. S.; NORTON, D. P. The balanced scorecard. Boston: Harvard Business School, 1996.

KEEGAN, D. P.; EILER, R.G.; JONES, C. R. Are Your Performance Measures Obsoletes? Management Accounting, v.70, n.1, p.45-50, 1989 .

KENNERLEY, M.; NEELY, A. A framework of the factor affecting the evolution of performance measurement systems. International Journal of Operations \& Production Management. v.22, n.11, p.1222-1245, 2002.

cross ${ }^{\text {ref }}$

LIMA, R. C.; ALVES, N. A. O Premio nacional da qualidade e o Balanced Scorecard. Livre Iniciativa. Limeira, 2004.

LUNA, S. V. Planejamento de pesquisa: uma introdução. São Paulo: EDUC, 1997.

LYNCH, R. L.; CROSS, K. F. Measure Up!: Yardsticks for continuous improvement. Blackwell Publishers, Cambridge, 1991

MARR, B.; SCHIUMA, G. Business performance measurement \pm past, present and future. Management Decision. v.41, n.8, p..680-687, 2003.

cross ${ }^{\text {ref }}$

MARTINS, R. A. Sistemas de medição de desempenho: um modelo para estruturação do uso. Tese - Escola Politécnica, Universidade de São Paulo, São Paulo, 1998.

MARTINS, R. A. Use of performance measurement systems: some thoughts towards a comprehensive approach. Paper from Second International on Performance Measurement. University of Cambridge, 19-21 July. Published on Performance Measurement 2000 - Past, Present and Future. Edited by Andy Neely, Center for Business Performance of Cranfield, University. 2000.

NEELY, A. Measuring Business Performance. Profile Books, The Economist Newspaper, 1998.

NEELY, A. D.; ADAMS, C. Perspectives on Performance: The Performance Prism. Gee Publishing, London, 2000.

NEELY, A. D. The evolution of performance measurement research: developments in the last decade and a research agenda for the next. International Journal of Operations \& Production Management. v.25, n. 12, p.1264-1277, 2005 .

NEELY, A. The performance measurement revolution: why now and what next? International Journal of Operation and Production Management, v.19, n.2, p.205-228, 1999.

cross ${ }^{\text {ref }}$

OLVE, N. G.; ROY, J.; WETTER, M.; MÜLLER, M. C. Condutores da performance: um guia prático para o uso do balanced scorecard; Rio de Janeiro: Qualitymark, 2001.

PEIXINHO, F. C. O modelo de gestão estratégica baseado no Balanced Scorecard para uma empresa pública. Monografia - Universidade Federal do Rio de Janeiro. Rio de Janeiro, 2003.

PORTER, M. E. Estratégia Competitiva - Técnicas para Análise de Indústrias e da Concorrência. 7a ed. Rio de Janeiro: Campus, 1997.

PORTER, M. E. Vantagem Competitiva. Rio de Janeiro: Campus, 1992. 
RUY, M; MARTINS, R. A. Perfil da pesquisa científica em medição de desempenho: uma análise dos Anais do ENEGEP de 2003 a 2005. Anais do XXVI ENEGEP. Fortaleza, 2006.

SINK, D. S.; THOMAS C. T. Planejamento e Medição para a Performance..Rio de Janeiro: Qualitymark, 1993.

SOARES, I. S. Gestão Estratégica de Custos. Rio de Janeiro, 2003.

SLACK, N. Administração da Produção. São Paulo: Atlas, 1997.

TAKASHINA, N. T.; FLORES, M. C. X. Indicadores da qualidade e do desempenho: como estabelecer metas e medir resultados. Rio de Janeiro: Qualitymark, 1996.

YIN, R. K. Estudo de Caso: planejamento e métodos. Porto Alegre: Bookman. 2001.

\section{Dados dos autores:}

\section{Nome completo: Elias Hans Dener Ribeiro da Silva}

Filiação institucional: Pontifícia Universidade Católica do Paraná - PUCPR

Departamento: Programa de Pós-Graduação em Engenharia de Produção em Sistemas - PPGEPS

Função ou cargo ocupado: Bolsista PIBIC/CNPq - Engenharia de Produção

Endereço completo para correspondência (bairro, cidade, estado, país e CEP): Marechal Floriano Peixoto, 3512 apto 06 - 80220-001 - Curitiba-PR

Telefones para contato: (41) 3524-8755 / (41) 8874-7268

e-mail:eliashans@hotmail.com

\section{Nome completo: Edson Pinheiro de Lima}

Filiação institucional: Pontifícia Universidade Católica do Paraná - PUCPR

Departamento: Programa de Pós-Graduação em Engenharia de Produção em Sistemas - PPGEPS

Função ou cargo ocupado: Professor Titular

Endereço completo para correspondência (bairro, cidade, estado, país e CEP): Imaculada Conceição, 1155 - Prado Velho - 80215-901 - Curitiba-PR

Telefones para contato: (41) 3271-1333

e-mail:e.pinheiro@pucpr.br

\section{Nome completo: Sérgio Eduardo Gouvêa da Costa}

Filiação institucional: Pontifícia Universidade Católica do Paraná - PUCPR

Departamento: Programa de Pós-Graduação em Engenharia de Produção em Sistemas - PPGEPS

Função ou cargo ocupado: Professor Titular

Endereço completo para correspondência (bairro, cidade, estado, país e CEP): Imaculada Conceição, 1155 - Prado Velho - 80215-901 - Curitiba-PR

Telefones para contato: (41) 3271-1333 
Recebido para publicação em: 29/05/2009

Aceito para publicação em: 07/09/2009

e-mail:s.gouvea@pucpr.br 